\title{
The Administrative Implications for University Libraries of the New Cataloging Code
}

Mr. Ellsworth is director of libraries, University of Colorado, Boulder.

Now that it is my turn to level my lance at the sails of this dangerous and seemingly impregnable windmill, I wonder why I was chosen to speak for university libraries. Perhaps because someone had to be the goat and because my ignorance could be written off on the grounds of youth and innocence. Or, perhaps because $\mathrm{Mr}$. Coney felt that someone who had been exposed to the chilling and biting drafts which sweep around the Chicago Graduate Library School corridors would be sufficiently tough to stand up under the rebuttal blasts which are sure to follow the approach $I$ intend to make.

If you think that each university library should have a catalog which will aim at giving a reasonably complete bibliographic description of all its books regardless of the nature and importance of these books, the purpose for which they were bought and used, and the characteristics of the clientele using the books, if, in other words, you accept the assumptions underlying our present cataloging practices, then I think you have to take one of two attitudes toward the new code.

You may say that the wise cataloger will welcome the codification and will use it as a useful tool and not as an end in itself, or you may feel that the code will drag us deeper into that kind of perfectionistic cataloging which Dr. Osborn has described so ably. ${ }^{1}$

But as an administrator, I dare not accept these assumptions and I think the publication of the new code is a propitious moment for a critical analysis of them. I present the following eleven reasons for pursuing this analysis.

\section{Reasons for Analysis}

First, from the time of volume one of the Library Journal, there has been much critical discussion about the relation between catalogs and bibliographies, and the proponents of subject cataloging have embarked upon a program without recognizing and meeting the objections of the proponents of subject bibliographies as a substitute for subject cataloging. In fact, I have thought, after reading the literature, that the latter group were more logical, scholarly, and realistic than the first even though they were not able to organize themselves into a successful pressure group in the profession.

Second, a casual scanning of the new code with its hundreds of rules and exceptions to rules leads me to wonder how we are to expect our student bodies to comprehend such a system in a manner that will enable them to use the resulting tool. One is forced to the conclusion that our catalogs are librarians' and not users' tools.

1 Osborn, A. D. The Crisis in Cataloging. American Library Institute, I94I. 
Third, observation of the behavior of students leads me to the conclusion that we are aiming far over their heads. The majority seem merely interested in locating a specific book title which someone has asked or told them to read. A minority approach the catalog from the subject point of view and these aren't interested in the subject approach as we librarians think of it.

Fourth, discussion with members of the faculty, at Colorado and elsewhere, reveals that many of them do not even know what the catalog has to offer and when this is explained to them, they wonder why in the world librarians go to all this trouble to produce a tool which has so little relationship to their use of the records of scholarship.

Fifth, one of the truisms of educational psychology is that learners differ in their ability, the extent of their knowledge, and the rate at which they acquire knowledge. Yet, we offer one single tool which we assume can be used by all students and members of the faculty with equal success.

\section{Differences in Materials}

Sixth, if it can be whispered that the catalog's clientele differs in its characteristics, it can be shouted that the publications listed in our catalogs differ in purpose, scope, method, significance, suitability, and relevance. A bibliographic tool which ignores these differences must necessarily fall short of its aim of bringing the reader and the book together.

Seventh, every adult in this audience has lived to witness the out-moding of most of the truths which were regarded as immutable in his or her youth. In all realms of knowledge the researcher is carefully peeling off layer after layer of prejudice, ignorance, misconception, and mistaken re- lationships. At the same time, our knowledge is increasing at a geometric ratio and our terminology is changing as rapidly.

As an administrator, I see that we cannot afford to change our cataloging terminology fast enough to keep within sight of the front lines of research. Nor can most of us afford large enough staffs to do the reclassification which needs to be done if our subject classifications are to avoid being the laughing stock of an alert contemporary. As a librarian, I am ashamed to admit that my profession has been unable to think of a way in which these two problems can be met. I am not satisfied with the plea that we need to take the long-time point of view, because I see no indication that the rate of change will slow down. It is more likely to increase.

Eighth, as a pseudo or sometime social scientist, I know that in time of crisis, and especially in the period immediately preceding the crisis, the pamphlet and other elusive materials become of supreme importance. I see that we cannot afford to handle these materials in our regular cataloging process, and so we resort to other means of handling them. Social science scholars have been known to wonder why we don't use these "other means" more often. They seem so simple and inexpensive.

\section{Duplication}

Ninth, I see within my own state several state-supported institutions of higher learning and two private institutions all with curricula which overlap to some extent and all with book collections that duplicate one another to some extent. Each of these institutions maintains its own cataloging staff and catalogs its own books, even though a substantial share of this work is outright duplication. 
And what is true of Colorado is even more true of the country as a whole.

Timid voices which have raised this question before have been smashed down with the answer that each university is different from all the rest and each one therefore has to adapt its catalogs and classifications to meet its own unique needs. Unique indeed! Some of us are wondering if our own incompetence isn't what we mean by our uniqueness.

You may say the Library of Congress card system answers my objection, but if so, can you show me a library that reduced the size of its cataloging staff after it started to use Library of Congress cards? Or, can you show me one that does not study the Library of Congress cards and alter them to such an extent that the savings are practically wiped out?

Tenth, a university exists primarily for a community of scholars. There are many in our midst that are not scholars, but even so the majority have some degree of $W$ issendurst. If the catalog is the best tool we can devise for scholars, it would seem logical that catalogers should either be scholars themselves, or at least be scholarly enough to understand the language of scholarship. Frankly, it does not seem to me that many of us have been successful in staffing our departments with large numbers of catalogers who from the point of view of education and training have reached a high enough level to produce scholarly cataloging. How many Ph.D.'s are there among our catalogers? Even if we could get such people, the salaries we pay, the academic status we offer, the working conditions we impose, and the kind of work we expect would soon drive most real scholars out of the field. We administrators are guilty of tolerating a situation when we ought to be protesting, nationally, in a manner that would lead to a different course of action.

\section{Catalogs and Bibliographies}

Eleventh, I have read the literature of the subject rather carefully, and I find that we librarians have not come to grips with the problem of the relation between catalogs and bibliographies. We have come to assume that our subject catalogs coupled with our subject classifications are subject bibliographies or can be used as substitutes for them. It is within the realm of this problem that we have strayed farthest from realities. We defend our assumptions by saying that the catalog shows what one library owns but the bibliography shows what is available elsewhere. For the beginning student, this distinction may be all right, but for the researcher, it is meaningless. For what purpose are our union lists and catalogs, our interlibrary loan services, and our microfilms, if not to enable the scholar to secure whatever he needs? In other words, for the researcher, when he uses the library as a researcher, the catalog is slightly irrelevant.

Scholars have found that our catalogs do not reveal the literature they need in the way in which they need it when they need it. Consequently, they have developed various kinds of abstracts and indexes, such as Chemical Abstracts, Biological $A b$ stracts, Chemical Reviews, Review of Education Research, Annual Bibliography of the Modern Language Association, etc.

And still, we librarians usually go on with our subject cataloging without regard to these publications and without seeming to understand why they exist. And so with other bibliographic work. How many of us, for instance, now that the new Cambridge Bibliography of English Literature is available, will integrate this tool 
with our future subject cataloging of English literature? How many of us know how to do this or know why we would be doing what we would be doing?

These are some of the implications of the new code for me as a university library administrator. It seems to me that some of these questions will have to be faced by the profession. The solution will come only if we start by examining the fundamental assumptions underlying our practices.

In order that my paper may not seem entirely negative in tone and purpose, permit me to suggest an outline of how the problem might be met.

\section{Suggestions}

First, we must free ourselves of the burden which we are carrying as a result of our assumption that cataloging for all types of libraries is much the same problem. The university as a social institution exists for a different reason than does the public library-even the large public library, the junior college, or the liberal arts college. Its purpose, its clientele, and its materiel are different. It follows, therefore, that its cataloging will be different. This means, specifically, that the Library of Congress Card Division might well study the possibility of issuing various kinds of cards for various kinds of libraries, if it is to continue issuing cards.

Second, we should study the three fundamental needs of location, identification, and subject approach in terms of the various groups in our clientele and of the various kinds of publications. And in making this analysis we should constantly keep in mind the specific functions of the catalog and the bibliography.

For example, the learner who is a beginner in a specific subject may be faced with the problem of locating a specific title or he may be looking for titles which will outline the field and furnish definitions. The learner who is a specialist or a researcher in the same specific subject needs location, identification, and subject guides which are entirely different from those needed by the beginner. Our catalogs minimize these differences as do most of the existing subject bibliographies. Our problem is one of providing tools which will recognize and meet these differences.

Third, we should assume that it is now possible to organize our approach to the problem on a national basis, not on the individual library as a base.

If, for example, what we need is less subject cataloging in card form and more printed bibliographies of various kinds for various purposes, then instead of maintaining hundreds of small groups of catalogers all over the country, why not group these people together in a few centers and put them to work compiling bibliographies?

We should not forget that the Library of Congress, the H. W. Wilson Company, and the publishers of the various indexing and abstracting services are all essential segments of the same circle. At the present time the work of these three groups is disastrously unrelated. The three should be brought together into one single program. Who will have the imagination and ingenuity to do this?

\section{Changing Eras}

Fourth, we must remember that an era in American history is ended. No longer can institutions embark upon enterprises or maintain practices without reckoning the costs or disregarding them even if the product seems good. Most of us will return from this conference facing the prob- 
lem of reducing our expenditures to meet a declining enrolment. Most of us have already cut so deeply that further cuts can be made only by major amputations. We have been spending staggering sums on cataloging our collections and I am inclined to think that our faculties and administrations do not think the money well spent. The arguments we have been using will, I think, be insufficient.

Fifth, it is a commonly heard observation that we librarians resist changes in our technical processes with a fervor that approaches fanaticism. It is my guess that unless we can break ourselves of this rather primitive attitude toward our technical processes, we will lose control of them just as we are losing control of university libraries through our failure to understand that a community of scholars needs a library "of the scholar, by the scholar, and for the scholar."

If my remarks today seem irrelevant to the question, please accept my explanation that these are the implications which I as an administrator of a university library see in the new code. I speak for myself, not for my colleagues.

\section{The Significance of the Joint University Libraries}

(Continued from page 107)

possible. Through the plans which you have perfected and through the building which you have added to the enduring resources of these three institutions, you have made a contribution to the extension and enrichment of education, the full significance of which cannot now be foreseen.

You have placed here at the center of these campuses a library building functionally designed to serve the varied interests of a distinguished community of students and scholars. Rooms for leisure and required reading and for the consultation of periodicals and reference works are available to the undergraduate; carrels in the stacks and special reading rooms are at the disposal of the graduate student ; seminars and studies are set apart for the faculty member; space for bibliographical apparatus, for microphotography, for the exhibition and use of special collections, and for the administration of the library as a whole, rounds out the full complement of the requirements of a modern university library. And all of these essentials have been skilfully organized in a building which in beauty of line and impressiveness of form stands as a symbol of the dignity and worth of learning. These are the obvious results of your conscious collaboration. But what you have so splendidly begun will, I am confident, demonstrate what has so frequently been demonstrated of the work of planners and builders heretofore. It will demonstrate that, splendid as have been your vision and accomplishment, you have actually planned and built better than you knew. 